\title{
Optimization Study of Integrated Scenarios on Cyclic Steam Stimulation (CSS) Using CMG STARS Simulator
}

\author{
Boni Swadesi $^{1)}$, Suranto ${ }^{1)}$, Indah Widiyaningsih ${ }^{1)}$, Martrida Jani ${ }^{1)}$ \\ ${ }^{1)}$ Petroleum Engineering Department, UPN Veteran Yogyakarta
}

\begin{abstract}
Reservoirs in the world contain various types of oil, the difference of these oil types can be seen in the viscosity value and also the value of the API degree. Reservoirs in the U-field contain heavy oil that cannot be produced conventionally so we need the EOR (Enhanced Oil Recovery) method. CSS is a method that uses high-temperature hot steam aimed at reducing the viscosity of the oil so that oil can be produced. In this final project, a simulation is conducted to study the effect of various parameters such as steam quality, injection rate, and cyclic period on CSS and also determine the best scenario for U-field. The simulation begins by determining the best steam quality value, then doing sensitivity to the expected injection rate, followed by sensitivity to the cyclic period. The best scenario results are the integration of optimum parameters, namely steam quality 0.8 , the injection rate of $550 \mathrm{BPD}$, and cyclic period of 20 days injection, 4 days soaking, and 60 days of production produce RF of $35.02 \%$.
\end{abstract}

\section{Keywords: EOR, CSS}

\section{INTRODUCTION}

Field-U which is in central Sumatra, Indonesia, has a reservoir containing heavy oil. Heavy oil is oil that has a high viscosity value with a small degree of API making it difficult to produce it conventionally. The data in this paper are secondary data obtained from OGRINDO ITB paper.

Heavy oil in the reservoir contains asphaltene which causes the low viscosity value of the oil so that it needs to be done the tertiary process with thermal, namely by injecting a steam which is intended to reduce its viscosity so that oil in the reservoir can be produced.

To produce oil in the reservoir requires an Enhanced Oil Recovery method with the aim of increasing the recovery from the reservoir. One of the Enhanced Oil Recovery methods that can be used to improve recovery in this field is Cyclic Steam Stimulation which is included in the thermal method. The mechanism is to reduce the viscosity value of the heavy oil so that the oil in the reservoir can be produced to the surface.

Evaluation is done by simulation methods. Simulations are performed on a simple model that represents D-wells, so that the model has the same value or in accordance with the D-field. The simulation is carried out with several scenarios, the first scenario is the sensitivity to the value of steam quality, the second scenario is the sensitivity of the injection rate, and the third scenario is the sensitivity to the cyclic period, which is the injection time of soaking and production.

Simulations will be carried out on the D-field well using CMG software which is expected to provide information on improving recovery from heavy oil in the U-field.

\section{PROBLEM STATEMENT}

The heavy oil in the U-field cannot be produced conventionally, therefore to be able to produce such heavy oil, the EOR (Enhanced Oil Recovery) method is needed. The EOR method used is CSS which is a thermal injection method. The mechanism of the CSS method is to inject a certain amount of heat into the reservoir, then the well is temporarily closed, which is intended to reduce the viscosity value of oil so that oil can be produced conventionally with the help of hot steam injection after which the well is produced.

In the U-field, the simulation is done first to determine the optimal steam quality value, after getting the optimal steam quality value, a simulation is performed to determine the optimum injection rate, the last is to determine which cyclic period can produce the largest RF value.

\section{BASIC THEORY}

Heavy oil is a type of oil that is viscous and cannot flow under normal reservoir conditions. Heavy oil is said to be heavy oil because it has a greater density and specific gravity value than conventional oil. A greater specific gravity value indicates a smaller API value, and in general, oil is said to be heavy oil if it has an API degree value below $20 \%$ and viscosity above $200 \mathrm{cP}$. 
EOR or Enhanced Oil Recovery is part of IOR (Improved Oil Recovery) that is, a method aimed at increasing the value of oil acquisition in any way. The EOR (Enhanced Oil Recovery) method is divided into 3 categories:

a. Thermal methods, such as prolonged steam injection, repeated steam injection (CSS), and in-situ combustion.

b. Chemical Flooding, such as polymers, surfactants-polymers, caustic flooding.

c. Miscible Gas Flooding, such as carbon dioxide, miscible hydrocarbons, and inert gas injection.

The EOR (Enhanced Oil Recovery) method is based on the type of reservoir fluid. For heavy oil reservoirs, the method that is considered the most efficient is the method that uses thermal as the main ingredient to reduce the viscosity of the reservoir fluid. Reservoir Geology and fluid properties determine the reservoir that is suitable for the process. Initial condition data such as temperature, pressure, depth of fluid characteristics such as viscosity value, fluid solubility, temperature, geological conditions, and others.

CSS is a process to increase oil recovery by injecting some heat into the reservoir. The aim is to reduce the viscosity value of oil and increase oil mobility so that it can be produced.

In the initial phase, steam injection is carried out for approximately 1 month and then closure of the well for several days for heat distribution, which is the spread of heat in the reservoir called Soaking. After the process is completed, a production process is carried out where oil can be more easily produced because of the reduced viscosity value of the oil. Oil production will increase drastically and then after a few months of production there will be a decrease in production because the value of oil viscosity goes up again, the reservoir temperature goes down again. Oil production decreases to the point where it is considered uneconomic, then the next cycle is carried out again, where one cycle consists of 3 phase, follows on until oil production is deemed to be commercially unprofitable. Field geology of the reservoir is needed to determine the possibility of heat loss and to know the heat distribution where the heat loss is when the injected steam disappears due to a fault around the reservoir.

\section{RESULT AND DISCUCCION}

\subsection{U-Field Reservoir}

The Reservoir model used in this study is a single well model formed in the CMG software.

Table 1. Data Characteristics of the Reservoir Model

\begin{tabular}{|c|c|}
\hline Simulator & CMG STARS \\
\hline Grid Type & Cartesian \\
\hline Grid System & Single-well \\
\hline Number of Grid (i x j x k) & $1 \times 1 \times 11$ \\
\hline Total Grid & 12 \\
\hline Top Grid Depth (ft) & 467 \\
\hline Reservoir Pressure (psi) & 200 \\
\hline Reservoir Temperature $\left({ }^{\circ} \mathrm{F}\right)$ & 100 \\
\hline Net Pay Thickness $(\mathrm{ft})$ & 59 \\
\hline Porosity & 0.4 \\
\hline Soi & 0.5 \\
\hline Permeability $(\mathrm{md})$ & 1126 \\
\hline
\end{tabular}

Table 2. Data of Fluid Reservoir Characteristics

\begin{tabular}{|c|c|c|}
\hline Parameters & Value & Unit \\
\hline Rock Compressibility & $58 \times 10-6$ & $1 / \mathrm{psi}$ \\
\hline Oil density & 58.9 & $\mathrm{lb} / \mathrm{cuft}$ \\
\hline Oil FVF & 1.067 & $\mathrm{RB} / \mathrm{STB}$ \\
\hline GOR & 19.2 & $\mathrm{SCF} / \mathrm{STB}$ \\
\hline Oil molecular weight & 283 & $\mathrm{lb} / \mathrm{lbmole}$ \\
\hline Gas molecular weight & 2.38 & $\mathrm{lb} / \mathrm{lbmole}$ \\
\hline Oil mole fraction & 0.95 & - \\
\hline Gas mole fraction & 0.05 & - \\
\hline Oil critical pressure & 774.4 & Psia \\
\hline Oil critical temperature & 248.6 & $0 \mathrm{~F}$ \\
\hline Gas critical pressure & 1014.09 & Psia \\
\hline Gas critical temperature & -60.31 & $0 \mathrm{~F}$ \\
\hline
\end{tabular}




\begin{tabular}{|c|c|c|}
\hline Oil heat capacity & 0.526 & BTU/cuft-0F \\
\hline Reservoir Thermal Expansion & $4 \times 10-4$ & Vol/vol/0F \\
\hline Overburden heat capacity & 38.4 & BTU/cuft- ${ }^{\circ} \mathrm{F}$ \\
\hline Underburden heat capacity & 38.4 & BTU/cuft- ${ }^{\circ} \mathrm{F}$ \\
\hline Overburden heat conductivity & 35 & Btu/ft day ${ }^{\circ} \mathrm{F}$ \\
\hline Underburden heat conductivity & 35 & Btu/ft day ${ }^{\circ} \mathrm{F}$ \\
\hline
\end{tabular}

Very important data in modeling using heavy oil is viscosity vs. temperature, it can be seen in Figure 1, the relative permeability curve can be seen in Figure 2.

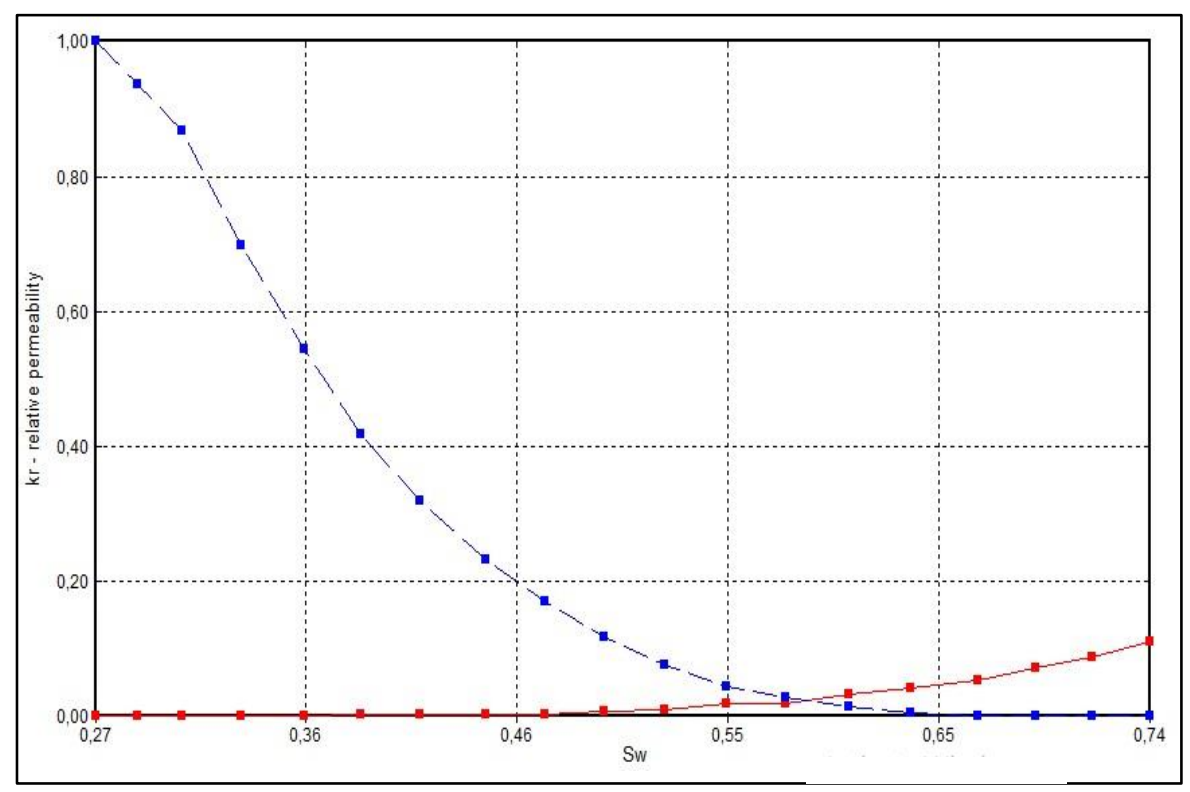

Figure 1. Temperature vs. Viscosity graph

\subsection{Simulation Results}

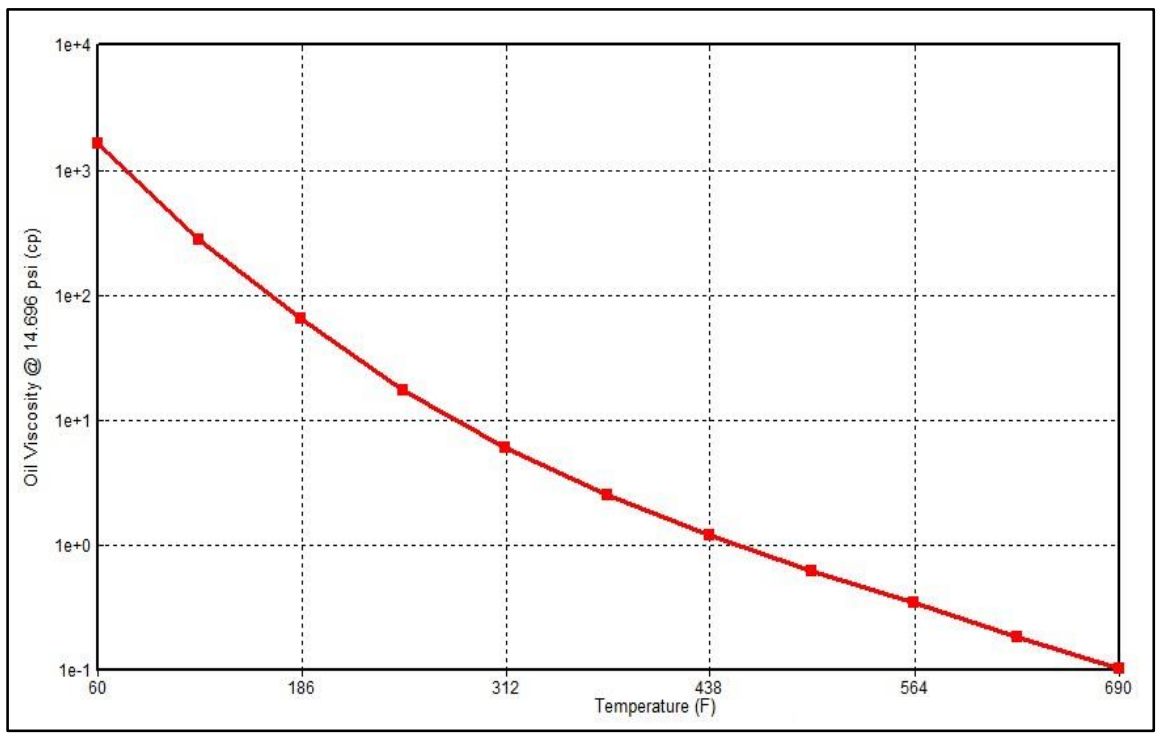

Figure 2. Oil-water relative permeability curves 


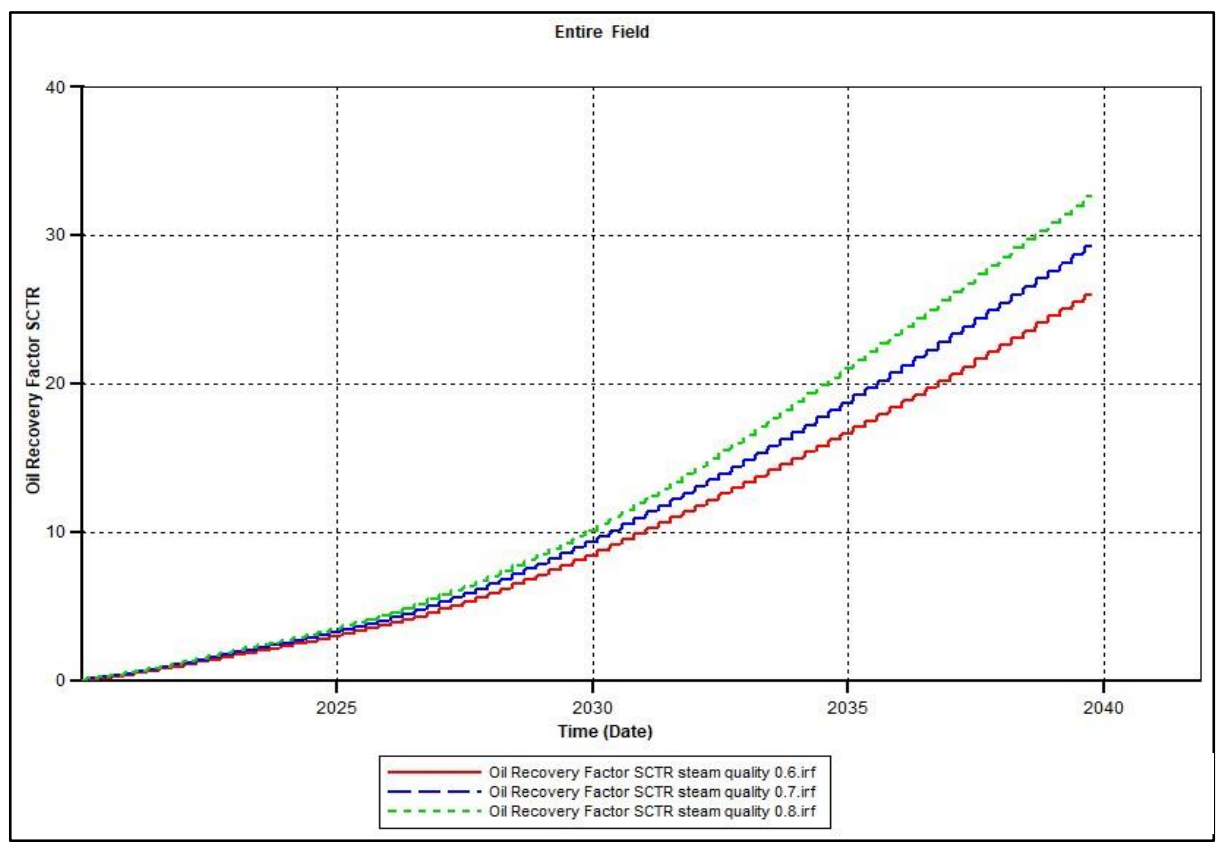

The simulation is done first to determine the optimum steam quality. In this scenario 1, sensitivity is carried out on the steam quality parameter $(0.6 ; 0.7 ; 0.8)$.Figure 3. Time vs. Recovery Factor Graph

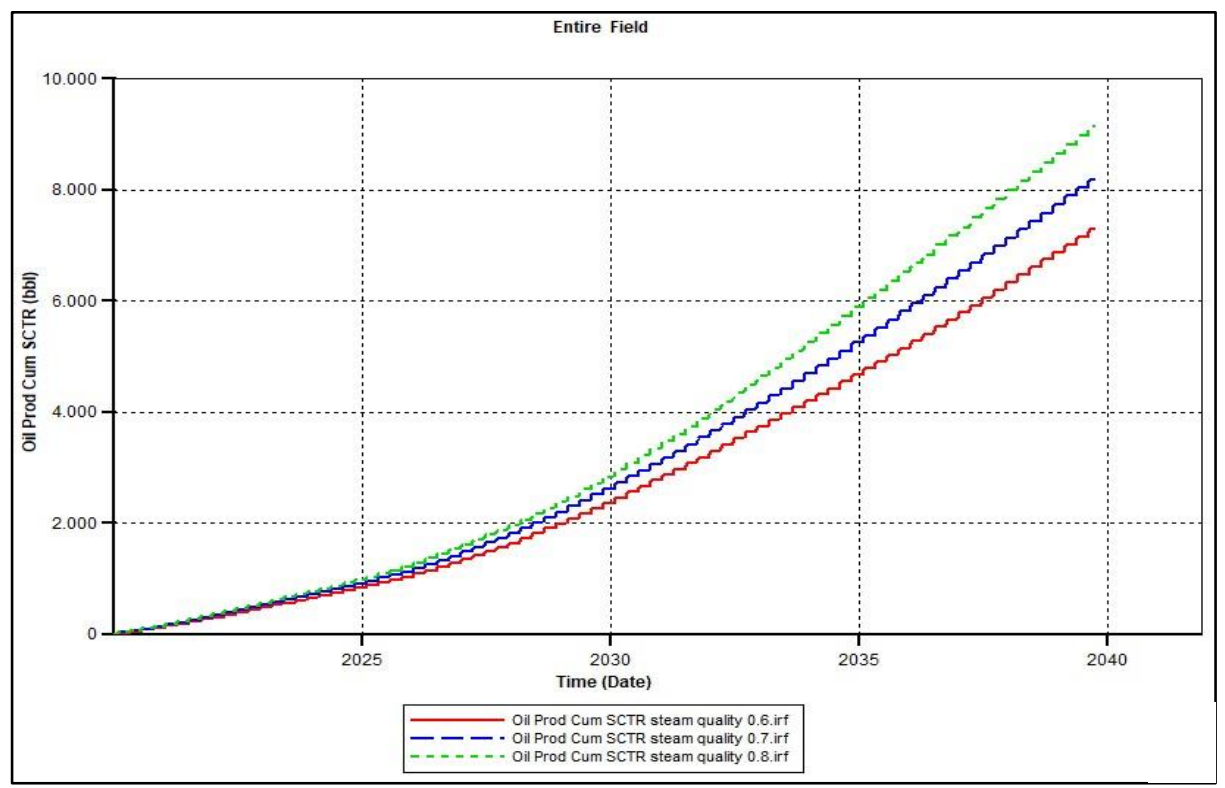

Figure 4. Time vs. Cumulative Oil Graph

Table 3. RF, NP, and CSOR data on various steam quality prices

\begin{tabular}{|c|c|c|c|c|}
\hline No. & $\begin{array}{c}\text { Steam } \\
\text { Quality }\end{array}$ & $\begin{array}{c}\text { Recovery } \\
\text { Factor }\end{array}$ & $\begin{array}{c}\text { Cumulative Oil } \\
(\mathrm{bbl})\end{array}$ & $\begin{array}{c}\text { CSOR } \\
(\mathrm{bbl} / \mathrm{bbl})\end{array}$ \\
\hline 1. & 0.6 & 26 & 7283.11 & 10 \\
\hline 2. & 0.7 & 29.21 & 8182.96 & 8.93 \\
\hline 3. & 0.8 & 32.61 & 9137.1 & 8 \\
\hline
\end{tabular}

In this scenario 1 , the optimum steam quality is steam quality 0.8 . With steam quality 0.8 can provide an RF value of $32.61 \%$ and CSOR value of the lowest of $8 \mathrm{bbl} / \mathrm{bbl}$. Of the 3 steam quality tested, the highest steam quality can provide the largest RF value because with large steam quality, the heat content in steam will also be greater, the amount of heat will result in lower viscosity, so oil mobility will be large and oil can easily flow to the surface.

After obtaining the optimum value of steam quality, the second scenario is carried out sensitivity to the injection rate $(350 ; 450 ; 550)$ using steam quality as big as 0.8 .CSS carried out for 20 years with a cyclic period of 20 injection days, 5 days soaking and 60 days of production. 


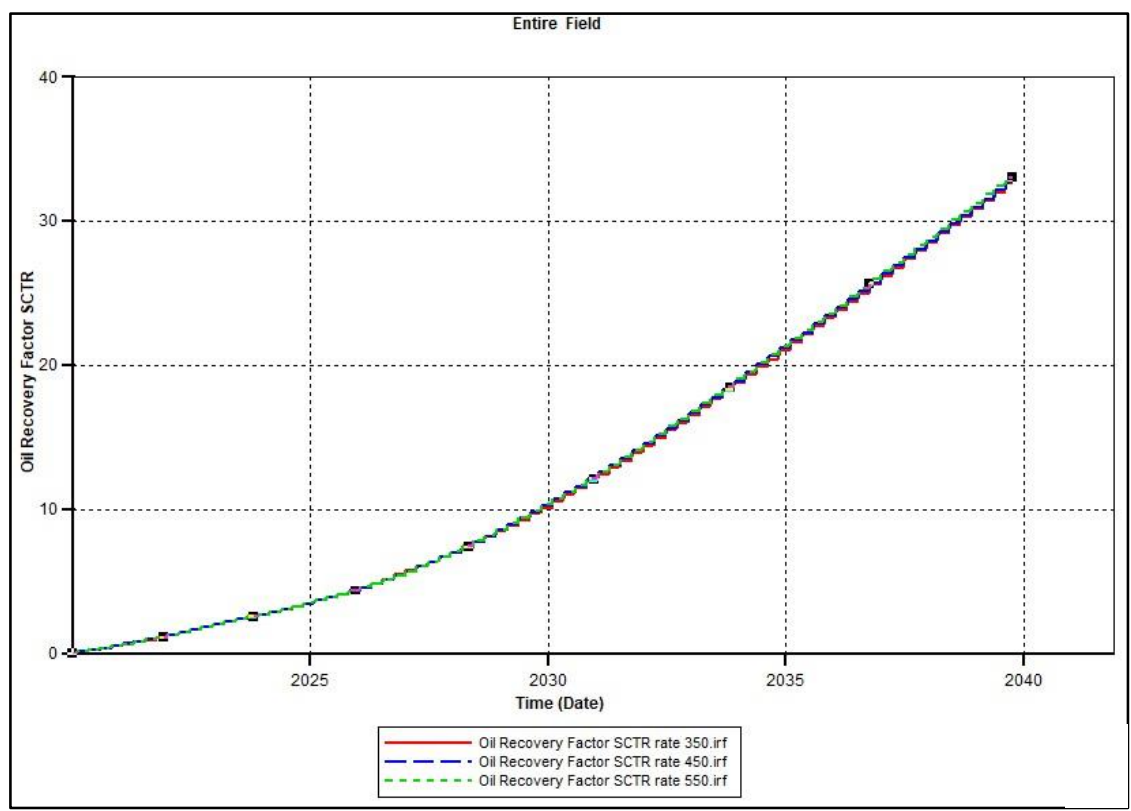

Figure 5. Time vs Recovery Factor Graph

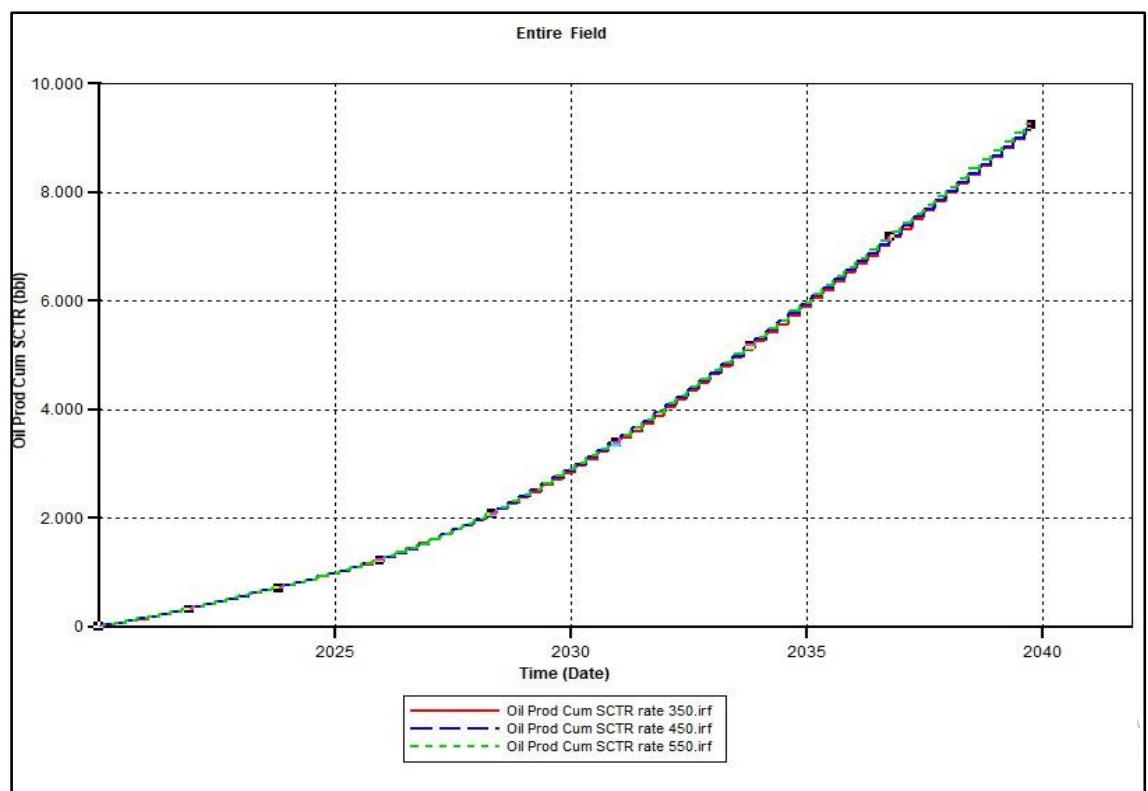

Figure 6. Time vs. Cumulative Oil Graph

Table 4. RF, NP, and CSOR data at various injection rate prices

\begin{tabular}{|c|c|c|c|c|c|}
\hline No. & $\begin{array}{l}\text { Steam } \\
\text { Quality }\end{array}$ & $\begin{array}{l}\text { Injection } \\
\text { Rate } \\
\text { (bpd) }\end{array}$ & $\begin{array}{c}\text { Recovery } \\
\text { Factor }\end{array}$ & $\begin{array}{c}\text { Cummulative } \\
\text { Oil (bbl) }\end{array}$ & $\begin{array}{c}\text { CSOR } \\
\text { (bbl/bbl) }\end{array}$ \\
\hline 1. & \multirow{3}{*}{0.8} & 350 & 32.61 & 9137.1 & 8 \\
\hline 2. & & 450 & 32.68 & 9156.14 & 8 \\
\hline 3. & & 550 & 33 & 9244.71 & 8 \\
\hline
\end{tabular}

The injection rate of 550 gives the highest RF value, the addition of the injection rate will also increase the NP value but not so influential, this is because the amount of injection rate in the sensitivity around the drill hole is saturated with the injection rate above. After sensitivity to the injection rate, the third scenario is to do sensitivity to the cyclic period (injection, soaking, production). In this scenario, it is run 6 times.

Figure 7. Time vs. Recovery Factor 

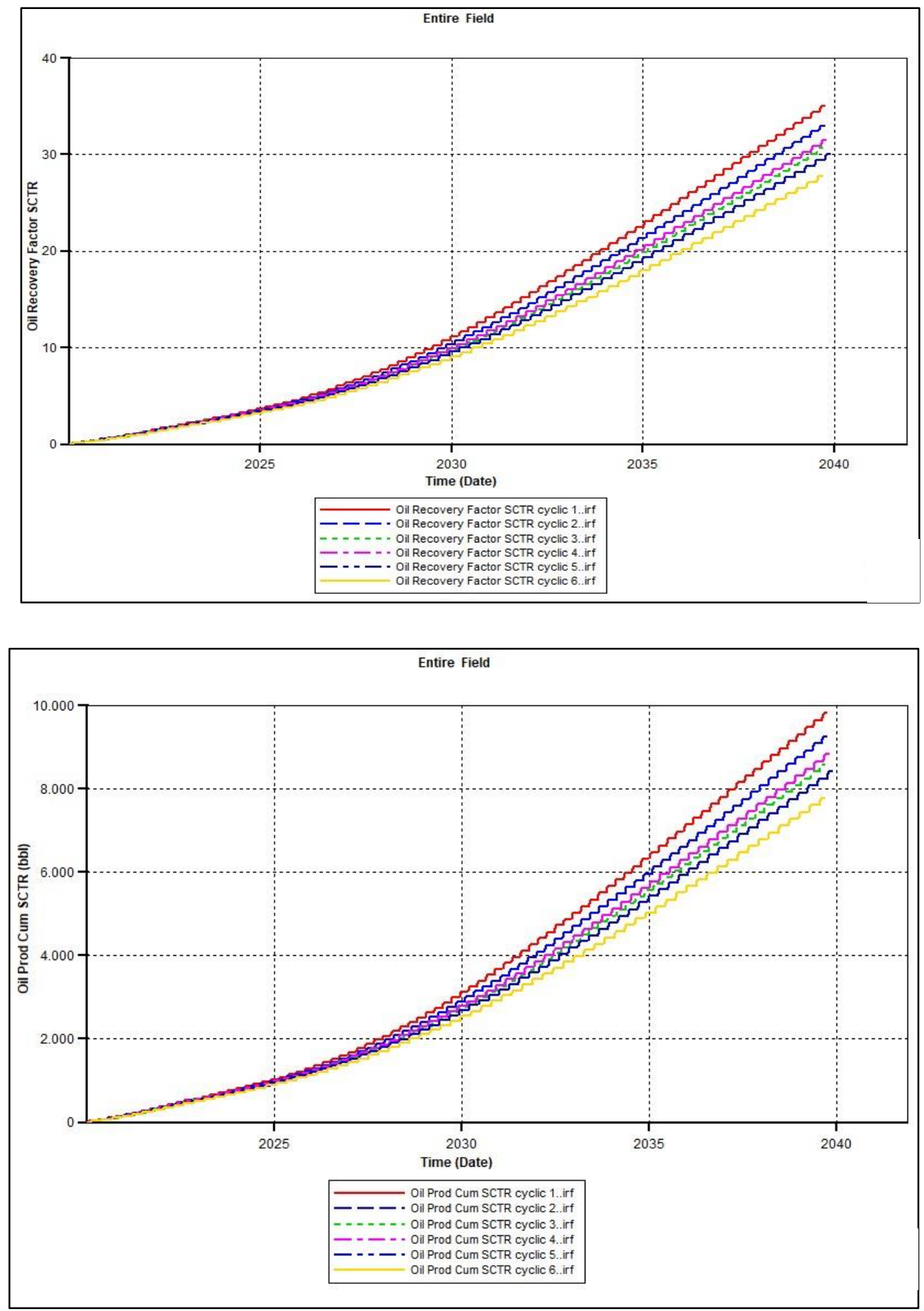

Figure 8. Time vs Cumulative Oil

Table 5. Cyclic Period Data

\begin{tabular}{|c|c|c|c|}
\hline Cyclic & $\begin{array}{c}\text { Injection } \\
\text { (day) }\end{array}$ & $\begin{array}{c}\text { Soaking } \\
\text { (day) }\end{array}$ & $\begin{array}{c}\text { Produksi } \\
\text { (day) }\end{array}$ \\
\hline 1 & 20 & 4 & 60 \\
\hline 2 & 20 & 7 & 60 \\
\hline 3 & 20 & 10 & 60 \\
\hline 4 & 30 & 4 & 60 \\
\hline 5 & 30 & 7 & 60 \\
\hline
\end{tabular}




\begin{tabular}{|l|l|l|l|}
\hline 6 & 30 & 10 & 60 \\
\hline
\end{tabular}

Table 6. RF, NP, and CSOR data on various cyclic period prices

\begin{tabular}{|c|c|c|c|c|c|c|}
\hline No. & $\begin{array}{l}\text { Steam } \\
\text { Quality }\end{array}$ & $\begin{array}{c}\text { Rate } \\
\text { Injeksi } \\
\text { (bpd) }\end{array}$ & $\begin{array}{l}\text { Cyclic } \\
\text { Period }\end{array}$ & $\begin{array}{c}\text { Recovery } \\
\text { Factor }\end{array}$ & $\begin{array}{c}\text { Cumulative } \\
\text { Oil (bbl) }\end{array}$ & $\begin{array}{c}\text { CSOR } \\
\text { (bbl/bbl) }\end{array}$ \\
\hline 1. & \multirow{6}{*}{0.8} & \multirow{6}{*}{550} & Cyclic 1 & 35.02 & 9812.08 & 8 \\
\hline 2. & & & Cyclic 2 & 33 & 9244.71 & 8 \\
\hline 3. & & & Cyclic 3 & 30.61 & 8576.1 & 8 \\
\hline 4. & & & Cyclic 4 & 31.49 & 8820.92 & 8 \\
\hline 5. & & & Cyclic 5 & 30.02 & 8409.48 & 8 \\
\hline 6. & & & Cyclic 6 & 27.74 & 7770.84 & 8 \\
\hline
\end{tabular}

In this third scenario, six runs are carried out to determine the effect of the cyclic period and to determine which scenario will be chosen from the integration of steam quality parameter, injection rate, and cyclic period that can provide optimum RF values. Judging from the graph, it can be compared to the same injection rate and different soaking periods, the lowest soaking time shows the highest RF value, this can occur because the longer the soaking time the heat loss will also be greater, the heat loss causes ineffectiveness of steam to reduce oil viscosity, consequently mobility is also not optimal, if viewed from the same soaking time with different injection times shows that with increasing injection time the acquisition of oil actually decreases because the area around the borehole has been filled with water.

\section{CONCLUSION}

Based on the simulation results obtained and the analysis that has been done, there are several conclusions that can be submitted, namely as follows:

1. At the end of scenario 1 simulation with CSS reservoir, RF prices are obtained and the optimum NP is $32.61 \%$ with steam quality 0.8 .

2. At the end of scenario 2 simulation with CSS, an optimum RF price of $33 \%$ is obtained with an injection rate of $550 \mathrm{BPD}$.

3. From the whole scenario, scenario 3 (steam quality 0.8 , injection rate $550 \mathrm{BPD}$, injection period 20 days, soaking 4 days, and 60 days production) was chosen because it produced the biggest RF value, that is $35.02 \%$.

\section{REFERENCES}

Butler, Roger M., “Thermal Recovery of Oil and Bitumen”, Prentice Hall, Englewood Cliffs,New Jersey, 1991.

Carcoana, Aurel, “Applied Enhanced Oil Recovery”, Prentice Hall, Englewood Cliffs, New Jersey, 1992.

D.W.Ho., et.al., "Efect of Steam Quality on Cyclic Steam Stimulation at Cold Lake, Alberta", SPE, Canada, 1990.

Gael, B.T., et al., "Development Planning and Reservoir Management in the Duri Steam Flood", SPE, Bakersfield, 1995.

Hong, K.C.:"Steamflood Reservoir Management-Thermal Enhanced Oil Recovery", PennWell Publishing Company, Tulsa, Oklahoma, 1994.

H.Niko., et al., "Experimental Investigation of Steam Soaking in a Depletion-Type Reservoir", SPE, Brunei, 1970.

Lumbantobing, Sudianto., Natalia, Sandra., and Silalahi, Henri., "Improving Oil Recovery and Injection Strategy in Shallow Reservoir (Rindu Reservoir) of Area 3 and 4 Duri Steam Flood”, SPE, Jakarta, 2011.

Sheng, James J., "Enhanced Oil Recovery Field Case", Gulf Professional Publishing Company, Lubbock, TX, 2013.

STARS., "STARS Version 2015 User's Guide", Computer Modelling Group Ltd., Calgary, 2015.

Tewari, Raj Deo., et al., "Successful Cyclic Steam Stimulation Pilot in Heavy Oilfield of Sudan", SPE, Kuala Lumpur, 2011.

Zhu, Z., et al., "Thermal Streamline Simulation: Steam Floods",SPE, Texas, 2011. 